\title{
LUGAR DE FALA E A DISCUSSÃO SOBRE COTA DE GÊNERO NAS ELEIÇÕES: UMA PERSPECTIVA DE COMPREENSÃO TRANSDISCIPLINAR A PARTIR DA MÚSICA “O QUE SE CALA"
}

\author{
Maxwel Gomes dos Santos* \\ Frederico de Andrade Gabrich ${ }^{* * *}$
}

\begin{abstract}
Resumo
A partir do método hipotético-dedutivo e do marco teórico estabelecido pela Constituição brasileira de 1988 sob o paradigma do Estado Democrático de Direito, esta pesquisa visa a analisar o problema da sub-representação feminina na política e nas casas legislativas, a partir da análise transdisciplinar do conceito de "lugar de fala", especialmente a partir da música "O que se cala", de Douglas Germano, gravada por Elza Soares, no álbum "Deus é Mulher", de 2018.

Palavras-chave: Lugar de fala. Cota de gênero. Eleições. Direito e arte. Direito e transdisciplinaridade.

\section{RIGHT TO SPEAK AND PLACE OF SPEECH ON GENDER QUOTA IN ELECTIONS: A PERSPECTIVE OF TRANSDISCIPLINARY UNDERSTANDING FROM "O QUE SE CALA" MUSIC}

\begin{abstract}
Based on the hypothetical-deductive method and the theoretical framework established by the Brazilian Constitution of 1988 under the paradigm of the Democratic State of Law, this research aims to analyze the problem of the under-representation of women in politics and in legislative bodies, based on a transdisciplinary analysis of the concept of the place of discourse and the right to speak in its various discursive possibilities, especially the theme "O que cala", by Douglas Germano, recorded by Elza Soares, on the album "Deus é Mulher", 2018.
\end{abstract}

Keywords: Right to speak. Gender quota. Elections. Law and art. Law and transdisciplinarity.

\section{INTRODUÇÃO}

O Direito, assim como a arte, são produtos da cultura, que só existem (subsistem) enquanto veículos de significação e ressignificação de fatos, coisas, pessoas ou estados.

\footnotetext{
* Mestrando em Direito (FUMEC/MG). Especialista Lato Sensu em Direito Eleitoral e Processual Eleitoral (CEUCLAR/SP). Professor de Ensino Superior na UNIMONTES. Analista Judiciário no TRE/MG. E-mail: maxwel.santos@unimontes.br

** Doutor, mestre e especialista em Direito Comercial (Empresarial) pela Universidade Federal de Minas Gerais - UFMG. Professor Adjunto da Universidade FUMEC (Belo Horizonte - MG). E-mail: fredericogabrich@fumec.br
} 
Direito e arte são, por assim dizer, um tipo de linguagem, que se verbaliza por imagens, sons, signos e cânones.

Compreender o outro e seu locus no Direito é, como na arte, uma maneira de olhar e expressar a visão. Há muitas maneiras de se enxergar uma pintura, há muitas maneiras de se ouvir uma mesma música e há muitas maneiras de se declamar um poema ou contar uma mesma narrativa. Nesse ambiente multifacetado pela linguagem e pelas imagens, o Direito e a arte se encontram.

Este estudo, a partir do método hipotético-dedutivo e do marco teórico estabelecido pela Constituição brasileira de 1988 sob o paradigma do Estado Democrático de Direito, busca analisar o problema da sub-representação feminina na política e nas casas legislativas, a partir da análise transdisciplinar do conceito de "lugar de fala", especialmente a partir da música "O que se cala", de Douglas Germano, gravada por Elza Soares, no álbum "Deus é Mulher", de 2018.

O fio condutor da discussão perpassa a identificação do lugar de fala no debate sobre cota de gênero nas eleições, numa perspectiva de compreensão transdisciplinar mediada pela música. A reflexão contempla o lugar de fala nas suas diversas possibilidades que, de forma atenta e sem silenciar a voz do outro, permite participar da construção discursiva do Estado Democrático de Direito.

O trabalho está estruturado de modo que o primeiro capítulo discute a problematização do lugar do outro e propõe o Direito e a arte como medio de compreensão dessa realidade. Na seção seguinte, problematiza-se o lugar de fala, tendo por fio condutor a discussão acerca da dissimetria de gênero na política e a sub-representação feminina nos parlamentos. Em seguida, amplia-se o debate acerca do lugar de fala e as implicações da subrepresentação feminina na política sob o paradigma do Estado Democrático de Direito. Finalmente, fazem-se as considerações finais, retomando as principais contribuições deste estudo.

\section{A PROBLEMATIZAÇÃO DO LUGAR DO OUTRO E O DIREITO: A ARTE COMO MEDIO DE COMPREENSÃO}

Para que serve o Direito? Quem é o outro? Em que lugar eles - o Direito e o outro (se é que) se encontram? A problematização do outro e do lugar que este ocupa é para o 
Direito uma questão fundamental que diz respeito à própria razão de ser do Direito enquanto fato social que valoriza condutas e prescreve comportamentos. Como propõe Miguel Reale, o Direito está presente, ainda que de forma indireta, em cada ação de um ser humano que se relacione com outro. Entretanto, ele, o Direito, consiste numa criação/experiência cultural humana e exprime-se numa linguagem que lhe é própria (REALE, 2001).

Falar do Direito e do outro pode ser também falar de uma experiência coletiva, que forma a base de narrativas, como uma experiência do passado que se reconstroi em um processo de readaptação que, cada vez mais, passa pelas mãos do narrador artesanal, tal qual a mão do oleiro que molda um vaso (OTTE, 1999, p. 14).

E conforme adverte Luís Alberto Brandão Santos:

Toda narrativa veicula um olhar: um certo modo de ver, conceber, transitar no
espaço daquilo que é narrado. Assim, toda narrativa constitui a figura de um
narrador: um narrador que torna possível, que a cria e, simultaneamente, é criado por
ela. O olhar do narrador é aquele que impulsiona, através dos seus movimentos, a
narrativa. No entanto, há narrativas que se alimentam do desejo de ressaltar tais
movimentos, de vasculhar nuances. Narrativas que exploram as possibilidades e
limitações desse olhar, transformando-o em um importante objeto a ser
minunciosamente narrado. (SANTOS, 1999, p. 25).

É nesse sentido que se compreende que a língua significa algo diferente da capacidade geral de falar e, sim, designa uma estrutura particular de sistema, de onde emerge uma nova problemática que tende, ao menos de início, a destacar o problema do discurso, que precisa ser libertado do seu exílio marginal e precário (RICOEUR, 1976, p. 14).

O outro encontra, assim, no Direito, seu lugar no discurso, na ação comunicativa. De acordo com Jürgen Habermas (1987), o discurso argumentativo pode distinguir-se em três aspectos. Considerado como processo, se trata de uma forma de comunicação menos frequente, pois pressupõe condições ideais de fala. Como procedimento, se considera uma forma de interação submetida a uma regulação especial, onde o entendimento está regulado numa divisão cooperativa do trabalho entre os locutores do discurso e, finalmente, como argumentação, com o objetivo de produzir argumentos pertinentes, por meio dos quais se busca um reconhecimento intersubjetivo para a pretensão de validade que o proponente apresenta como hipótese, sob cujos argumentos, uma opinião pode transformar-se em saber.

Aqui chega-se ao ponto em que se compreende o Direito e a arte como um tipo de linguagem discursiva. E a arte como uma possível fonte de mediação entre o Direito e a compreensão do outro. O Direito e a arte se encontram exatamente quando podem ser encarados como uma tentativa do ser humano em colocar alguma ordem no caos que é a 
própria existência e comunicar sua subjetividade ao outro, de modo que a vida em sociedade seja possível. O Direito e a arte não são produtos da natureza, tais como o vento, uma pedra, uma árvore ou um rio. Direito e arte são produtos da cultura, que só existem (subsistem) enquanto veículos de significação e ressignificação de fatos, coisas, pessoas ou estados. Direito e arte são, por assim dizer, um tipo de linguagem, que se verbaliza por imagens, sons, signos e cânones. Antes de ser tido por ciência, o Direito foi arte. No dizer de Celso, "o Direito é a arte do bom e do equitativo" (CELSO, apud PINHO; NASCIMENTO, 1981, p. 23).

Compreender o outro e seu lugar no Direito é, como na arte, uma maneira de olhar e expressar a visão. Há muitas maneiras de se olhar uma pintura, há muitas maneiras de se ouvir uma mesma música e há muitas maneiras de se declamar um poema ou contar uma mesma narrativa. Nesse ambiente multifacetado pela linguagem o Direito e a arte se encontram.

Nessa mesma perspectiva, Bordieu afirma, que:

De fato, caberá ao leitor julgar se, como creio (por tê-lo eu próprio experimentado),
a análise científica das condições sociais da produção e da recepção da obra de arte,
longe de a reduzir ou de a destruir, intensifica a experiência literária: como se verá a
propósito de Flaubert, ela parece anular de início a singularidade do "criador" em
proveito das relações que a tornam inteligível, apenas para melhor redescobri-la ao
termo do trabalho de reconstrução do espaço no qual o autor encontra-se englobado
e "incluído como um ponto". Conhecer como tal esse ponto do espaço literário, que
é também um ponto a partir do qual se forma um ponto de vista singular sobre esse
espaço, é estar em condição de compreender e de sentir, pela identidade mental com
uma posição construída, a singularidade dessa posição e daquele que a ocupa [...]
(BORDIEU, 1996, p. 14).

Uma outra maneira possível de se ver a arte e o Direito consiste em indagar o que eles nos dizem a respeito das culturas em que foram produzidos. Perquirir até que ponto eles são realistas. Analisá-los em termos e quanto ao modo de produção, identificando padrões intrínsecos e extrínsecos. E, o que se afigura mais importante, não se limitar a ver/contemplar a arte e o Direito, mas também falar sobre eles (WOODFORD, 1983). No dizer de Susan Woodford, "Encontrar palavras para descrever e analisar obras de arte oferece, com frequência, o único caminho que nos poderá ajudar a progredir de um mero olhar passivo para um ver ativo e discernidor" (WOODFORD, 1983, p. 13).

A vida em sociedade só é possível porque existe a comunicação e as linguagens. Direito e arte são, assim, formas de comunicação e de linguagem. Nesse sentido, pode-se dizer que o Direito opera no nível gramatical da linguagem: estabelece regras, reconhece princípios, cuida de como as pessoas devem agir/falar e de como as instituições devem ser. A 
arte opera no nível vocal e visual da linguagem: expressa sentimentos, nomina fatos e pessoas, provoca sensações e torna erudita a banalidade que é o quotidiano.

\section{LUGAR DO OUTRO NO DIREITO E LUGAR DE FALA: UMA PROBLEMATIZAÇÃo NECESSÁRIA}

Falou-se no capítulo anterior que o lugar que o outro ocupa no Direito é essencialmente um lugar discursivo. E todo discurso traz consigo narrativas que de certa forma reconstroem um passado e perpassam o presente com um olhar prospectivo, de futuro. Daí, que o lugar do outro se encontra numa experiência coletiva, que forma a base da narrativa. Tudo isso remete à uma discussão atual, que passa pelo Direito, mas não se reduz a ele, acerca do que vem a ser o lugar de fala.

Primeiramente, é preciso que se diga que não há um conceito único acerca do que é lugar de fala e ao redor do termo polêmicas se constroem acerca da sua real utilidade como meio de compreensão da vida e do outro.

Nessa reflexão, Habermas (2016, p. 127) contribui ao exprimir que "Na identidade do Eu se exprime a relação paradoxal de que o Eu enquanto pessoa em geral é igual a toda outra pessoa, mas quando indivíduo se diferencia por excelência de todos os outros indivíduos".

Daniela Mendes dos Santos et all. (2018, p. 1) expressam que "O conceito de lugar de fala tem se tornado algo discutido cotidianamente, principalmente nas redes sociais, onde membros de grupos historicamente silenciados têm utilizado de narrativas para dar voz aos seus saberes e experiências". E, juntamente com Djamila Ribeiro (2020) identificam que o ambiente das redes sociais virtuais tem propiciado disputas e rachaduras nas narrativas hegemônicas, uma vez que, quando sujeitos não pertencentes a locais privilegiados utilizam desses ambientes para contar a sua história e marcar posicionamento, estão suscetíveis a serem considerados hostis, por estarem rompendo com um ciclo de silenciamento.

Ribeiro esclarece que:

[...] não há uma epistemologia determinada sobre o termo lugar de fala especificamente, ou melhor, a origem do termo é imprecisa. Acreditamos que este surge a partir da tradição de discussão sobre feminist standpoint - em uma tradução literal 'ponto de vista feminista' - diversidade, teoria racial crítica e pensamento decolonial. As reflexões e trabalhos gerados nessas perspectivas, consequentemente, foram sendo moldados no seio dos movimentos sociais, muito marcadamente no 
debate virtual, como forma de ferramenta política e com o intuito de se colocar contra uma autorização discursiva. (RIBEIRO, 2020, p. 105/106).

Para fins deste estudo, dada a relevância que se acredita ter o tema lugar de fala na linguagem discursiva do Direito e suas implicações na consolidação do Estado Democrático de Direito, conceituar-se-á lugar de fala como um instrumento teórico metodológico para explicar as vozes discursivas a partir da localização de grupos distintos, buscando compreender suas posições sociais e os capitais simbólicos, de modos específicos, a partir das condições de construção do grupo. (RIBEIRO, 2020).

Esse conceito apresentado de lugar de fala retoma a ideia de Bordieu (1998), para quem lugar é um espaço ocupado do ponto de vista relacional, o que traz imbricada a noção de intersubjetividade de sujeitos com o ambiente. Já o falar é apropriar-se de estilos expressivos já constituídos no e pelo uso e objetivamente marcados por posições hierarquizadas por grupos no e para o mercado.

Discutir o lugar de fala, traz consigo a pergunta subjacente se é possível o subalterno falar. E se possível for para ele falar, deve fazê-lo de que locus? Nesse contexto obliterado do sujeito subalterno, conforme Spivak (2010), o "sujeito em opressão", ocupa clandestinamente o espaço da forma de consciência, com os termos não reconhecidos de sua própria articulação. E a questão se agrava quando se considera a posição subalterna feminina, na medida em que “a construção ideológica de gênero mantém a dominação masculina. Se no contexto da produção colonial, o sujeito subalterno não tem história e não pode falar, o sujeito subalterno feminino está ainda mais na obscuridade.” (SPIVAK, 2010, p. 66-67).

Coerente com o pensamento de SPIVAK (2010), Ribeiro (2020) ressalta que o falar não se restringe ao ato de emitir palavras, mas de poder existir. Algo como refutar a historiografia tradicional e a hierarquização de saberes consequentes da hierarquia social. E complementa refletindo acerca da complexidade do lugar de fala ocupado pela mulher, especialmente na condição de mulher negra:

Como explica Collins, quando falamos de pontos de partida, não estamos falando de experiências de indivíduos necessariamente, mas das condições sociais que permitem ou não que esses grupos acessem lugares de cidadania. Seria, principalmente, um debate estrutural. Não se trataria de afirmar experiências individuais, mas de entender como lugar social ocupado por certos grupos restringe oportunidades.

Ao ter como objetivo a diversidade de experiências, há a consequente quebra de uma visão universal. Uma mulher negra terá experiências distintas de uma mulher branca por conta de sua localização social, vai experienciar gênero de uma outra forma. (RIBEIRO, 2020, p. 111-112). 
À essa altura, deve-se reconhecer o lugar de fala como um recurso que não importa em falar em nome de outrem e sim participar do discurso reconhecendo as diversas vozes, sem silenciá-las, bem como reconhecendo por vezes a posição privilegiada de quem se propõe a discutir a partir de uma outra posição.

Nesse sentido, encarar, por exemplo, o debate que perpassa a dissimetria de gênero na política e a sub-representação feminina nos parlamentos não implica falar em nome do gênero feminino e nem pelo gênero feminino, mas ouvir atentamente suas vozes e posicionarse sabendo do lugar privilegiado do qual muitas vezes se fala sobre o lugar do outro. Eis uma das dificuldades na compreensão do debate acerca do lugar de fala.

Conforme Ribeiro:

Temos, pois, de reformular o primeiro critério - o discurso como evento - de um modo mais dialético, a fim de se tomar em consideração a relação que constitui o discurso enquanto tal, a relação entre evento e significado. Mas, antes de conseguirmos apreender esta dialética como um todo, consideremos o lado "objetivo" do evento da fala. (RIBEIRO, 2020, p.21).

Aqui, mais uma vez a arte, por meio da música, oferece uma chave de leitura importante na compreensão das diversas vozes discursivas e nas inúmeras possibilidades de participação do discurso. Um exemplo de como isso pode ocorrer é o uso da arte, especialmente da música, para dizer o que precisa ser dito, mesmo em tempos nos quais a ordem do Direito é o silêncio: "mesmo calada a boca resta o peito / silêncio na cidade não se escuta" (BUARQUE; GIL, 1973).

No dizer de Roselaine Andrade Tavares e Frederico de Andrade Gabrich:

A música popular brasileira, amplamente acessível a toda a população, seja por meio do rádio, da internet ou de aplicativos, contém os mais variados exemplos de conexão com o Direito, aproximando-o do cotidiano das pessoas, dos problemas do mundo presente, especialmente os nacionais e regionais (TAVARES; GABRICH, 2020, p. 52).

Por vezes, o Direito e a arte se misturam em composições únicas, nas quais um vocaliza o outro. É o que acontece, por exemplo, na música "O que se cala”, de Douglas Germano:

\author{
Mil nações \\ Moldaram minha cara \\ Minha voz \\ Uso pra dizer o que se cala \\ O meu país \\ É meu lugar de fala
}


Mil nações

Moldaram minha cara

Minha voz

Uso pra dizer o que se cala

Ser feliz no vão, no triste, é força que me embala

O meu país

É meu lugar de fala

Mil nações

Moldaram minha cara

Minha voz

Uso pra dizer o que se cala

Ser feliz no vão, no triste, é força que me embala

O meu país

É meu lugar de fala

Pra que separar?

Pra que desunir?

Por que só gritar?

Por que nunca ouvir?

Pra que enganar?

Pra que reprimir?

Por que humilhar?

E tanto mentir?!

Pra que negar

Que o ódio é que te abala?

O meu país

É meu lugar de fala

Mil nações

Moldaram minha cara

Minha voz

Uso pra dizer o que se cala

Ser feliz no vão, no triste, é força que me embala

O meu país

É meu lugar de fala

Pra que explorar?

Pra que destruir?

Por que obrigar?

Por que coagir?

Pra que abusar?

Pra que iludir?

E violentar

Pra nos oprimir?

Pra que sujar o chão da própria sala?

Nosso país

Nosso lugar de fala

O meu país

É meu lugar de fala

Nosso país

Nosso lugar de fala

Nosso país

Nosso lugar de fala (GERMANO, 2018). 
A música "O que se cala” foi gravada pela cantora Elza Soares e integra o repertório do álbum "Deus é Mulher", de 2018. A assinatura vocal e interpretação única de Elza Soares fizeram com que a música se confundisse com a história de vida da própria intérprete, o que assegura a ela o lugar de fala para dizer "o que se cala": mulher e negra. Elza já sofreu racismo e violência física, mas nunca se calou ou se deu por vencida. Hoje, nonagenária, reconhecida pelo público e pela crítica, ela segue atual e usa sua voz para cantar a liberdade e falar por si e pelas brasileiras e brasileiros que não podem levantar sua voz ou são silenciados (direta ou indiretamente, especialmente por falta de oportunidades).

A música sob análise e a trajetória de vida da intérprete permitem contemplar o simesmo como outro, seguindo a via da enunciação, a partir dos atos de fala, de forma pragmática, empregando a linguagem em contextos determinados de enunciação. Na composição e na música, o "eu-tu" da interlocução se exterioriza num "ele/ela" sem perder a capacidade de se autodesignar e interiorizar-se como sujeito que diz (RICOEUR, 2019).

Nestes tempos em que cerceamentos à liberdade de expressão e o discurso de ódio se espraiam pelo Brasil, em "O que se cala", Elza Soares distingue uma coisa da outra e contempla, a partir do Brasil mesmo, nosso lugar de fala, uma sociedade miscigenada (mil nações moldaram minha cara) e dividida pelos discursos de ódio e pela violência concreta (pra que sujar o chão da própria sala?). Mas ela canta a esperança - "Ser feliz no vão, no triste, é força que me embala".

Em "O que se cala", o horizonte é a liberdade e, em uma perspectiva habermasiana, é a síntese discursiva das diversas vozes, dos diversos atores (mil nações moldaram minha cara) que, "no meu país" tem seu "lugar de fala". Contempla-se assim, o lugar de fala nas suas diversas possibilidades discursivas que, de forma atenta e sem silenciar a voz do outro, permite participar da construção também discursiva do Estado Democrático de Direito.

\section{LUGAR DE FALA E SUB-REPRESENTAÇÃO FEMININA NA POLÍTICA: IMPLICAÇÕES SOB O PARADIGMA DO ESTADO DEMOCRÁTICO DE DIREITO}

Assumida posição no lugar de fala, importa, neste passo, ingressar no debate acerca de uma questão que ainda permanece crucial: em que pese as mulheres terem conquistado o direito ao voto ainda em 1934 e a Constituição de 1988, além de garantir a universalidade do direito ao voto, ter assumido o compromisso de construir uma sociedade calcada na dignidade 
da pessoa humana, na cidadania e no reconhecimento dos valores democráticos da liberdade e da igualdade, a sub-representação política das mulheres ainda reflete a desigualdade que caracteriza as relações de gênero na esfera pública e espaços de poder.

Discute-se neste capítulo o problema da sub-representação feminina na política em geral e nas casas legislativas em particular, tendo por norte a perspectiva transdisciplinar do conceito de "lugar de fala", especialmente a partir da música "O que se cala", que reconhece o nosso país como nosso lugar de fala..

\subsection{A quota de gênero nas eleições e o lugar de fala do legislador brasileiro}

É preciso que se diga sem tergiverssações: o lugar de fala do legislador brasileiro é o do homem branco e e integrante das classes sociais mais abastadas. Isto fica evidente, por exemplo, a partir da análise do fato de que na Câmara Federal, dos 513 parlamentares que a compõem, 85\% são homens, $75 \%$ são brancos, $80 \%$ possuem curso superior completo. As profissões predominantes (60\%) são as de empresário, advogado, médico, administrador, engenheiro, agropecuarista, economista e bacharel em direito (BRASIL, Câmara Federal, [2021]).

A representatividade na Câmara Federal tem especial significado porque deve refletir em alguma medida o perfil das brasileiras e brasileiros, uma vez que, teoricamente, os Deputados Federais representam o povo brasileiro.

O Senado, por sua vez, representa os Estados no sistema federativo brasileiro. Entretanto, a realidade representativa do Senado Federal não destoa daquela identificada na Câmara Federal: 85\% dos senadores são homens. (BRASIL, Senado Federal, 2021).

A legislação reflete o lugar de fala dos seus produtores e estes, como detentores de um espaço de fala, escuta e influência privilegiados, não se movem para superar as dissimetrias do mundo da vida. Este é o provável motivo pelo qual a principal ação afirmativa adotada pelo Brasil para tentar equalizar a participação das mulheres na formação dos parlamentos vem da década de 1990 e consiste na reserva de cota de gênero nos registros de candidatura para as eleições proporcionais. Reserva esta que há mais de 25 anos vem se mostrando ser apenas simbólica.

Primeiramente, a Lei $n^{\circ}$ 9.100/1995 (BRASIL, 1995) fixou uma cota de $20 \%$ do número de vagas passíveis de registro pelos partidos ou coligações e, posteriormente, a Lei 
no 9.504/1997 (BRASIL, 1997) ampliou essa cota para 30\%. Permitiu, porém, a Lei no 9504/97, que os partidos políticos lançassem candidatura no limite de até 150\% das vagas em disputa e, se concorressem coligados, o percentual total de candidaturas registradas seria de até $200 \%$ das vagas disputadas. Isso, de certa forma, permitiu diluir o percentual de candidaturas femininas no universo total de candidaturas registradas.

Ademais, os partidos políticos, ao longo dos anos, descumpriram sistematicamente a cota de gênero, seja interpretando-a como uma recomendação e não uma imposição legal, seja não preechendo a cota simplesmente. Em razão disso, a Lei no 12.034/2009 (BRASIL, 2009) deixou expresso que a cota deveria ser aplicada sobre o número de candidatos apresentados, não bastando apenas a reserva de vagas.

Observa-se que, passados mais de 25 anos da implantação da cota de gênero nas eleições, desde o advento da Lei $n^{\circ}$ 9.100/1995, essa ação afirmativa não logrou produzir os resultados esperados, uma vez que o número de mulheres eleitas para o parlamento continuou sendo pequeno em todas as eleições que se seguiram.

Com efeito, a reserva de contas nas eleições tal qual se encontra em vigor se insere no rol de leis simbólicas, que a par de normalizar situações complexas e de ampla repercussão social, o faz sem considerar os reais efeitos produzidos pela legislação. No momento em que se escreve este artigo, por exemplo, o Congresso Nacional discute a aprovação de uma ampla reforma eleitoral que, no entanto, no que diz respeito à superação da desigualdade de gênero continua no âmbito simbólico, com alguns retrocessos, sem que se faça a substituição por um modelo discutido com a sociedade e, sobretudo, com as mulheres, destinatárias da política afirmativa em comento (BRASIL, Agência Câmara, 2021).

$\mathrm{Na}$ superação das desigualdades de gênero na política, é essencial que se conceda às mulheres como interessadas o lugar de fala que lhes cabe. E que a sociedade participe também do debate de forma que se construam soluções negociadas, refletidas, mensuráveis e, sobretudo, democráticas.

\subsection{A quota de gênero nas eleições e seus reflexos no financiamento de campanha e na propaganda eleitoral}

Além do descumprimento da cota de gênero pelos partidos políticos ao longo da vigência da norma que estabeleceu a reserva de vagas para as mulheres nos registros de 
candidatura, um problema sempre apontado é o subfinanciamento das campanhas femininas (ASSIS, 2017).

O financiamento das campanhas eleitorais é um assunto bastante amplo, que vai além da questão da desigualdade de gênero, mas também passa por ela. Com efeito, na medida em que se discute a origem dos recursos que podem financiar as campanhas eleitorais: se somente recursos públicos, somente recursos privados ou de forma mista, por exemplo, passa-se pela questão de gênero, quando, independentemente da origem do recurso, discutemse os aportes às campanhas femininas.

Hoje, no Brasil, desde o julgamento da ADI 4650/2015, em que o Supremo Tribunal Federal reconheceu a inconstitucionalidade das doações feitas por pessoas jurídicas às campanhas eleitorais, vigora o sistema misto, em que o financiamento se dá por recursos advindos de fundos públicos e de doações de pessoas naturais.

Em 2018, no julgamento da ADI 5617, o Supremo Tribunal Federal também considerou inconstitucional dispositivo do artigo $9^{\circ}$ da Lei $\mathrm{n}^{\circ} 13.165 / 2015$, que estabelecia o percentual mínimo de 5\% e máximo de $15 \%$ do montante do Fundo Partidário destinado ao financiamento das candidaturas femininas. O entendimento fixado foi de que a destinação de recursos do Fundo Partidário às candidaturas deveria ser na exata proporção dos registros efetuados de candidatos de ambos os sexos, respeitado o patamar mínimo de $30 \%$ da cota de gênero, prevista no artigo 10 , parágrafo $3^{\circ}$, da Lei $n^{\circ}$ 9.504/1997.

A partir desse julgamento pelo Supremo Tribunal Federal, o Tribunal Superior Eleitoral passou a determinar o respeito ao patamar mínimo de proteção às candidaturas femininas fixado em $30 \%$, na Lei ${ }^{\circ}$ 9.504/1997, tanto no que se refere à reserva de vagas para registro de candidaturas, como também em relação ao percentual de recursos mínimos a serem empregados no financiamento das candidaturas femininas e também no tempo de propaganda eleitoral gratuita.

Assim, desde as eleições de 2020, o percentual mínimo a ser observado tanto de aplicação dos recursos do Fundo Partidário, como do Fundo Especial de Financiamento de Campanha - FEFC e na distribuição do tempo de propaganda eleitoral gratuita no rádio e na TV é o mesmo da cota de gênero, ou seja, 30\%, no mínimo.

Os efeitos desse novo entendimento do Tribunal Superior Eleitoral nas eleições municipais de 2020 também merecem estudos posteriores mais detalhados, a fim de que se verifiquem seus reflexos nas eleições. Contudo, ainda percebe-se que a dissimetria 
permanece. Poucas mulheres, mesmo com as novas regras a respeito do financiamento de campanha, conseguiram se eleger.

A recém-promulgada Emenda Constitucional no 111/2021, aplicável já a partir das Eleições Gerais de 2022, estabeleceu que os votos dados a mulheres e pessoas negras serão contados em dobro para efeito da distribuição dos recursos dos fundos partidário e eleitoral nas eleições de 2022 a 2030. Assim, fica a expectativa, para se analisar a partir do próximo pleito eleitoral se essa política afirmativa contribuirá para a ampliação dos espaços de poder da mulher brasileira (BRASIL, Agência Senado, 2021).

Nas eleições de 2020, as vereadoras eleitas correspondem a $16 \%$ do total de eleitos, enquanto que os homens correspondem a $84 \%$ dos total de vereadores eleitos. Entretanto, as mulheres representam 52,5\% do eleitorado (BRASIL, 2020).

Assim, vislumbra-se que o passo a ser dado para avançar na superação da desigualdade de gênero talvez seja não a reserva de um patamar mínimo de 30\% nos registros de candidaturas e nem a reserva de vagas nos parlamentos. Acredita-se que uma possível medida eficaz, de lege ferenda, seja a definição de registros entre candidaturas masculinas e femininas, na mesma proporção em que esses gêneros compõem o eleitorado e a população, ou seja, aproximadamente $52,5 \%$ de registros de candidaturas femininas.

Com uma medida dessa natureza, os partidos políticos inevitavelmente teriam que investir na formação de quadros femininos e na viabilização de candidaturas femininas competitivas. Medidas desse tipo, aliadas à mesma proporcionalidade do financiamento e do tempo de propaganda, possivelmente assegurariam mais justiça e uma maior igualdade de oportunidades na saída da disputa.

\subsection{A sub-representação feminina nos parlamentos e o déficit de legitimidade democrática}

A incompatibilidade da sub-representação feminina na política com o paradigma do Estado Democrático de Direito precisa ser discutida pela sociedade, num debate franco e comprometido realmente (e não apenas formalmente) com a sua superação. Conquanto não seja possível afirmar que a eleição de mais pessoas do gênero feminino por si só melhoraria de forma automática o nível do debate público ou a qualidade do Poder Legislativo, resta evidente, por outro lado, que a dissimetria que hoje se observa traz consigo um déficit de 
legitimidade democrática, seja sob o ponto de vista da democracia representativa, seja sob o ponto de vista da participação cidadã.

Conforme destacam Bruna Isabelle Simioni Silva e Jussimara de Oliveira Rosa de Paula:

O que as mulheres sempre buscaram e, ainda hoje, buscam seu espaço na sociedade,
visto que sempre foram tratadas com inferioridade, não é novidade. A desigualdade
das mulheres é existente desde o Brasil Colônia, no qual havia a reprodução de uma
"formação de invisibilidade e emudecimento da mulher". (SILVA; PAULA, 2021,
p. 158).

Quando se fala do paradigma do Estado Democrático de Direito, a noção de paradigma que se adota neste artigo parte da concepção de Thomas Kuhn (2013), para quem a ciência é construção humana, social e histórica, na qual o cientista trabalha a partir de modelos geralmente aceitos pela comunidade científica. É por meio desses modelos, os paradigmas, que as teorias se estruturam juntamente às suas aplicações e por meio delas, até que sejam superadas e surja um novo paradigma., dialeticamente. De acordo com Kuhn:

Uma nova teoria é sempre anunciada juntamente às suas aplicações a uma determinada gama concreta de fenômenos naturais; sem elas não poderia nem mesmo candidatar-se à aceitação científica. Depois de aceitas, essas aplicações (ou mesmo outras) acompanharão a teoria nos manuais onde os futuros cientistas aprenderão seu ofício. As aplicações não estão lá simplesmente como um adorno ou mesmo como documentação. Ao contrário, o processo de aprendizado de uma teoria depende do estudo das aplicações, incluindo-se aí a prática na resolução de problemas, seja com lápis e papel, seja com instrumentos num laboratório. (KUHN, 2013, p. 76).

Como construção humana, social e histórica, o paradigma do Estado Democrático de Direito é o modelo estruturante do Estado e das relações sociais no Brasil, a partir da Constituição da República de 1988. José Afonso da Silva (2020) descreve o Estado Democrático de Direito com como a evolução e superação dos paradigmas de Estado Liberal de Direito e do Estado Social de Direito. Para ele, O Estado Democrático de Direito configura um conceito novo, que incorpora os elementos componentes da ideia de Estado Democrático e de Estado Social de Direito, contudo os supera e tende a realizar a síntese do processo contraditório do mundo contemporâneo, como Estado promotor de justiça social, fundado na dignidade da pessoa humana.

A dignidade da pessoa humana e a cidadania, princípios acolhidos como fundamentos da República Federativa do Brasil já no artigo $1^{\circ}$ da Constituição de 1988, importam no reconhecimento do valor intrínseco e igual das pessoas, que coexistem com projetos de vida distintos e cuja participação discursiva nos processos decisórios e na política 
deliberativa conferem legitimidade à prórpria democracia representativa. Nesse sentido, conforme Álvaro Ricardo de Souza Cruz e Bonifácio José Suppes de Andrada:

O paradigma do constitucionalismo democrático contemporâneo, por sua vez, altera profundamente o significado do princípio da igualdade, fundamentdo-o na ideia de dignidade da pessoa humana. A noção de igualdade volta-se para o exame dos pressupostos procedimentais que devem ser observados no discurso de produção do Direito. Assim, exige-se o Direito de igual participação do cidadão em todas as práticas estatais. Paralelamente a essa perspectiva de igualdade aritmética inclusiva, defende-se o respeito aos Direitos humanos em função das particularidades individuais e coletivas. Associa-se à igualdade e à dignidade humana o princípio do pluralismo. (CRUZ; ANDRADA, 2017, p.119).

No que diz respeito à legitimidade, Gabrielle Tatith Pereira (2015) ensina que a política deliberativa consiste em algo dependente de uma cidadania capaz de participar dos processos institucionalizados de formação da opinião pública e capaz de transformar o poder comunicativo em poder administrativo pela ação comunicativa dos cidadãos.

Ainda no que toca à legitimidade e participação cidadã, o Estado Democrático de Direito, de acordo com Habermas, ultrapassa as fronteiras do político e transforma-se em um projeto de emancipação capaz de institucionalizar os processos de formação racional e coletiva da vontade:

O Estado democrático de Direito transforma-se num projeto, resultado e, ao mesmo tempo, mola de uma racionalização do mundo da vida, a qual ultrapassa as fronteiras do político. O único conteúdo do projeto é a institucionalização progressivamente melhorada dos processos de formação racional e coletiva da vontade, os quais não podem prejulgar os objetivos concretos dos participantes. Qualquer passo nesse caminho tem efeitos retroativos sobre a cultura política e as formas de vida, sem as quais não poderiam surgir formas de comunicação adequadas à razão prática. (HABERMAS, 1997, p. 276).

A Constituição de 1988, marcadamente pluridimensional, assume, assim, um compromisso com a cidadania e a integração das múltiplas vozes na conformação do próprio Estado como medium do poder que emana do povo. Nessa perspectiva, José Adércio Leite Sampaio fala de uma legitimidade democrática centrada na participação cidadã que, de acordo com Habermas, evidencia um caráter predominantemente procedimental, de forma livre e comunicacional, de modo que "todos se sintam parte do processo deliberativo, havendo atendimento da igualdade de voz, da consideração do ponto de vista dos afetados, do livre influxo de informações da sinceridade nas tratativas e do predomínio dos melhores argumentos na construção dos consensos.” (SAMPAIO, 2004, p. 25).

Habermas (1997) constata uma tensão entre a igualdade de Direito preconizada pelo modelo de Estado liberal e a igualdade de fato buscada pelo modelo de Estado de bem estar 
social, uma vez que um e outro modelo cometem o mesmo erro de reduzirem a ideia de justiça a uma igual distribuição de direitos, equiparados estes a bens que podem ser repartidos e possuídos. Com isso ignoram que a utonomia individual se dá no exercício de direitos que decorrem de normas legitimamente produzidas, em um processo racional e comunicativo, do qual participam os destinatários da norma como cidadãos livres e iguais (HABERMAS, 2010, p. 501-503).

Há, porém, no Brasil, uma dissonância entre a legitimidade compatível com o paradigma do Estado Democratico de Direito e a efetiva (eficaz) participação dos cidadãos e cidadãs no processo comunicativo de formação das normas jurídicas, no debate público e na composição das instâncias decisórias e de poder. Com efeito, embora constituam maior parte da população e dos eleitores, as mulheres ainda são sub-representadas na formação dos parlamentos (Congresso Nacional, Assembleias Legislativas/Distrital e Câmaras Municipais) e encontram fortes resistências em concorrerem nas eleições em igualdade de condições com candidatos masculinos.

A participação política feminina, certamente, é uma dessas frentes em que os avanços ainda são tímidos. Em que pese as mulheres terem conquistado o Direito ao voto ainda no ano de 1932, o modelo patriarcal que sempre orientou a sociedade e suas instituições no Brasil, relegou à mulher um papel secundário e subalterno, reservando alguns espaços materiais e simbólicos à hegemonia masculina. É assim na política, onde se admite a mulher como eleitora, mas não lhe franqueia o acesso como eleita.

Tem-se a consciência de que abordar o tema lugar de fala das mulheres na política importa refletir acerca dos elementos que se estruturam para que esse lugar se concretize tal como se apresenta. Importa em não fechar os olhos para a realidade e ser capaz de, como Elza Soares, cantar $O$ que se cala, com esperança "Ser feliz no vão, no triste, é força que me embala", pois, afinal "O meu país / É meu lugar de fala”.

\section{CONSIDERAÇÕES FINAIS}

Esta pesquisa buscou, a partir do método hipotético-dedutivo e de uma postura metodológica transdisciplinar, analisar e discutir a importância da problematização do outro e do locus que este ocupa no Direito, partindo-se da premissa de que isso para o Direito diz 
respeito a sua própria razão de ser enquanto fato social que valoriza condutas e prescreve comportamentos.

O fio condutor da discussão perpassou a identificação do lugar de fala na discussão sobre cota de gênero nas eleições, numa perspectiva mediada pela música $O$ que se cala, de Douglas Germano, gravada por Elza Soares, no álbum Deus é Mulher, de 2018. A reflexão contempla o lugar de fala nas suas diversas possibilidades discursivas que, de forma atenta e sem silenciar a voz do outro, permite participar da construção também discursiva do Estado Democrático de Direito.

Viu-se que o outro encontra no Direito o seu locus no discurso, na ação comunicativa, de viés habermasiano. Aqui chega-se ao ponto em que se compreende o Direito e a arte como um tipo de linguagem e a arte/música como uma possível fonte de mediação entre o Direito e a compreensão do outro. Com efeito, arte e Direito são produtos da cultura, que só existem (subsistem) enquanto veículos de significação e ressignificação de fatos, coisas, pessoas ou estados. Direito e arte são, por assim dizer, tipos de linguagem, ou melhor, de metalinguagem, que se verbalizam por imagens, sons, signos e cânones.

A discussão acerca do lugar que o outro ocupa no Direito traz consigo narrativas que de certa forma reconstroem um passado e perpassam o presente com um olhar prospectivo, de futuro. Daí, que o lugar do outro se encontra em uma experiência coletiva, que forma a base de narrativas. Tudo isso remete à uma discussão atual, que passa pelo Direito, mas não se reduz a ele, acerca do que vem a ser o lugar de fala e sua importância no debate atual acerca das cotas de gênero nas eleições e a sub-representação feminina nos parlamentos.

Abordou-se que o falar não se restringe ao ato de emitir palavras, mas a uma situação de poder existir. Algo que Djamila Ribeiro trata como refutar a historiografia tradicional e a hierarquização de saberes consequentes da hierarquia social.

Refletiu-se que o passo a ser dado para avançar na superação da desigualdade de gênero na porlítica talvez seja, de lege ferenda, a proporcionalidade de registros entre candidaturas masculinas e femininas, na mesma proporção em que esses compõem o eleitorado e a população. Com uma medida dessa natureza, os partidos políticos inevitavelmente teriam que investir na formação de quadros femininos e na viabilização de candidaturas femininas competitivas.

Ressaltando a transdisciplinaridade do estudo do Direito e a contribuição da arte, viuse que a música $O$ que se cala, gravada pela cantora Elza Soares no álbum "Deus é Mulher", 
de 2018 provoca reflexões sobre o locus que o si-mesmo e o outro ocupam nos espaços discursivos. Nessa música, Elza Soares proclama "o que se cala", a partir do Brasil como nosso lugar de fala comum: "o meu país é o meu lugar de fala".

\section{REFERÊNCIAS BIBLIOGRÁFICAS}

ASSIS, Izadora Lincoln. Represenatação feminina e financiamento de capanhas: histórico recente e novas perspectivas à luz da reforma eleitoral de 2015. Revice - Revista de Ciências do Estado, Belo Horizonte, v.2, n.2, p. 14-38, ago./dez. 2017. Disponível em: https://periodicos.ufmg.br/index.php/revice/article/download/5044/3110/15778. Acesso em: 22 ago. 2021.

BRASIL. Congresso Nacional. Câmara Federal. Deputados eleitos 2018. Disponível em: https://www.camara.leg.br/internet/agencia/infograficos-

html5/composicaocamara2019/index.html. Acesso em: 22 ago. 2021.

BRASIL. Congresso Nacional. Senado Federal. Agência Senado. Pacheco destaca esforço do Congresso para diminuir desigualdade de gênero. Disponível em:

https://www12.senado.leg.br/noticias/materias/2021/03/08/pacheco-destaca-esforco-docongresso-para-diminuir-desigualdade-de-genero. Acesso em: 22 ago. 2021.

BRASIL. Congresso Nacional. Senado Federal. Agência Senado. Minoria no Congresso, mulheres lutam por mais participação Senado Notícias. Disponível em:

https://www12.senado.leg.br/noticias/materias/2019/03/07/minoria-no-congresso-mulhereslutam-por-mais-participacao. Acesso em: 28 abr. 2021.

BRASIL. Congresso Nacional. Senado Federal. Agência Senado [2021]. Promulgada emenda constitucional da reforma eleitoral. Disponível em:

https://www12.senado.leg.br/noticias/materias/2021/09/28/promulgada-emendaconstitucional-da-reforma-eleitoral. Acesso em: 02 out. 2021.

BRASIL. Congresso Nacional. Senado Federal. Agência Câmara de Notícia. Mulheres representam 16\% dos vereadores eleitos no País [2020]. Disponível em:

https://www.camara.leg.br/noticias/708248-mulheres-representam-16-dos-vereadores-eleitosno-pais/. Acesso em: 05 jan. 2021.

BRASIL. Congresso Nacional. Senado Federal. Agência Câmara de Notícia. Câmara aprova texto-base da reforma eleitoral; votação continua nesta quinta-feira [2021]. Disponível em: https://www.camara.leg.br/noticias/793085-camara-aprova-texto-base-da-reformaeleitoral-votacao-continua-nesta-quinta-feira. Acesso em: 22 ago. 2021.BRASIL. Lei no 9.100, de 29 de setembro de $\mathbf{1 9 9 5}$. Estabelece normas para a realização daseleições municipais de 3 de outubro de 1996, e dá outras providências. Brasília, DF: Presidência da República, [2020]. Disponível em http://www.planalto.gov.br/ccivil_03/leis/L9100.htm\#: :text=LEI\%20N\%C2\%BA\%209.100 \%2C\%20DE\% 2029\%20DE\%20SETEMBRO\%20DE\% 201995.\&text=Estabelece\%20normas \%20para\%20a\%20realiza\%C3\%A7\%C3\%A3o,Art. Acesso em: 7 set. 2020. 
BRASIL. Lei $n^{0}$ 9.504, de 30 de setembro de 1997. Estabelece normas para as eleições. Brasília, DF: Presidência da República, [2020]. Disponível em http://www.planalto.gov.br/ccivil_03/leis/19504.htm. Acesso em: 7 set. 2020.

BORDIEU, Pierre. A economia das trocas linguísticas: o que falar quer dizer. 2. Ed. São Paulo: Editora Universidade de São Paulo, 1998.

BORDIEU, Pierre. As regras da arte. São Paulo: Companhia das Letras, 1996.

BUARQUE, Chico; GIL, Gilberto. Cálice. Marola Edições Musicais, 1973. Disponível em: http://www.chicobuarque.com.br/construcao/mestre.asp?pg=calice_73.htm. Acesso em: 22 ago. 2021.

CELSO, apud PINHO, Ruy Rebello; NASCIMENTO, Amauri Mascaro. Instituições de Direito Público e Privado: introdução ao estudo do Direito, noções de ética profissional.11. ed. São Paulo: Atlas, 1981.

CRUZ, Álvaro Ricardo Souza; ANDRADA, Bonifácio José Suppes de. Igualdade e discriminação. CRUZ, Álvaro Ricardo Souza (Org.). (O) outro (e) (o) Direito. v. 2, 2. ed. Belo Horizonte: Arraes, 2017.

GERMANO, Douglas. O que se cala. Deus é mulher. Intérprete: SOARES, Elza. Brasil: Deckdisc Polysom, 2018. Disponível em: https://www.vagalume.com.br/elza-soares/o-que-secala.html. Acesso em: 22 ago. 2021.

GIL, Antõnio Carlos. Como elaborar projetos de pesquisa. 4. ed. São Paulo: Atlas, 2002.

HABERMAS, Jürgen. Teoría de la acción comunicativa: racionalidade de la acción y racionalización social. REDONDO, Manuel Jiménez (Versão castellana). Madrid: Taurus, 1987. v. 1.

HABERMAS, Jürgen. Direito e democracia: entre facticidade e validade. Tradução: Flávio Beno Siebeneichler. Rio de Janeiro: Tempo Brasileiro, 1997. v. 2.

HABERMAS, Jürgen. Para a reconstrução do materialismo histórico. MELO, Rúrion (Trad.). São Paulo: Editora Unesp, 2016.

INSTITUTO BRASILEIRO DE GEOGRAFIA E ESTATÍSTICA. Coordenação de População e Indicadores Sociais. Estatísticas de gênero: indicadores sociais das mulheres no Brasil. n. 38. Rio de Janeiro: IBGE, 2018. Disponível em: https://biblioteca.ibge.gov.br/visualizacao/livros/liv101551_informativo.pdf. Acesso em: 13 set. 2020.

KUHN, Thomas Samuel. A estrutura das revoluções científicas. Tradução: Beatriz Vianna Boeira e Nelson Boeira. 12. ed. São Paulo: Perspectiva, 2013.

OTTE, Georg. A obra de arte e a narrativa: reflexões em torno do cânone em Walter Benjamin. OTTE, Georg; OLIVEIRA, Silvana Pessôa de (Org.). Mosaico crítico: ensaios 
sobre literatura contemporânea. Belo Horizonte: Autêntica, Núcleo de Estudos Latinoamericanos (NELAM - FALE -/UFMG), 1999.

PEREIRA, Gabrielle Tatith. Representação política, judicialização e democracia: o resgate do político por meio da interação entre o parlamento e a esfera pública. SILVA, Rafael Silveira e; MENEGUIN, Fernando Borato (Org.). Resgate da reforma política: diversidade e pluralismo no legislativo. Brasília : Senado Federal, Coordenação de Edições Técnicas, 2015.

REALE, Miguel. Lições preliminares de Direito. 25. Ed. São Paulo: Saraiva, 2001.

RIBEIRO, Djamila. O que é: lugar de fala?. Letramento: Belo Horizonte, 2020.

RICOEUR, Paul. Teoria da interpretação: o discurso e o excesso de significação. MOURÃO, Arthur (Trad.). Rio de Janeiro: Edições 70, 1976.

RICOEUR, Paul. O si-mesmo como outro. BENEDETTI, Ivone C. (Trad.). São Paulo: Martinsfontes, 2019).

SAMPAIO, José Adércio Leite. Teorias constitucionais em perspectiva: em busca de uma constituição pluridimensional. SAMPAIO, José Adércio Leite (Org.). Crise e desafios da constituição: perspectivas críticas da teoria e das práticas constitucionais brasileira. Belo Horizonte: Del Rey, 2004.

SANTOS, Daniela Mendes dos (Et all.). Lugar de fala: possibilidades e implicações para os estudos organizacionais. In: V Congresso brasileiro de estudos organizacionais, 2018, Curitiba-PR - Brasil. Anais do V Congresso brasileiro de estudos organizacionais, GT-1: Interseccionalidades nos Estudos Organizacionais: desigualdades de raça, gênero, sexualidade. Disponível em:

http://www.sisgeenco.com.br/sistema/cbeo/anais2018/MATRIZ/st1.html. Acesso em: 05 jun. 2021.

SILVA, José Afonso. Curso de Direito Constitucional Positivo. 43. ed., rev. e atual. São Paulo: Malheiros, 2020.

SILVA, Bruna Isabelle Simioni; PAULA, Jussimara de Oliveira rosa de. A concretização de Direitos a partir da sororidade e empoderamento feminino em "Felicidade clandestina" de Clarice Lispector. Mulher, Direito e literatura. SILVA, Bruna Isabelle Simioni; SILAS FILHO, Paulo (Org.). Salvador: Studio Sala de Aula, 2021. v. 1.

SPIVAK, Gayatri Chakravorty. Pode o subalterno falar?. ALMEIDA, Sandra Regina Goulart; FEITOSA, Marcos Pereira; FEITOSA, André Pereira (Trad.). Belo Horizonte: Editora UFMG, 2010.

TAVARES, Roselaine Andrade; GABRICH, Frederico de Andrade. Aplicação da música ao ensino do Direito. In: Rev. de Pesquisa e Educação Jurídica, Evento Virtual, v. 6, n. 1, Jan/Jun. 2020. Disponível em: https://indexlaw.org/index.php/rpej/article/view/6519. Acesso em: 23 jun. 2021. 
WOODFORD, Susan. A arte de ver a arte. CABRAL, Álvaro (Trad.). São Paulo: Círculo do Livro, 1983. 